Case Report

\section{Orgasmic coitus triggered stillbirth via placental abruption: A case report}

\author{
Márta Zsoldos ${ }^{1}$, Márton Vezér ${ }^{2}$, Henriette Pusztafalvi³ ${ }^{3}$ Bianka \\ Pencz ${ }^{4}$, Dora Hargitai ${ }^{4}$ and Attila Pajor ${ }^{2 *}$
}

'University of Pécs, Faculty of Health Sciences, Doctoral School of Health Sciences, Pécs, Hungary ${ }^{2}$ Semmelweis University Faculty of Medicine, Department of Obstetrics and Gynecology, Budapest, Hungary

${ }^{3}$ University of Pécs, Faculty of Health Sciences, Department of Health Development and Public Health, Pécs, Hungary

${ }^{4}$ Semmelweis University II. Department of Pathology, Budapest, Hungary

\section{Summary}

Sexual activity during healthy pregnancy is safe. There are little data on how coital activity affects outcome of the high-risk pregnancies. Hereby we report a case demonstrating that orgasmic coitus triggered placental abruption resulting in preterm stillbirth.

A 38-year-old 8-para, 12-gravida woman lived unmarriedly with a constant partner in low socioeconomic conditions. Her previous pregnancies included 7 deliveries without complication, two early miscarriages and two pregnancy terminations. Her present pregnancy was complicated with gestational hypertension successfully treated with nifedipine. She had coitus 2 to 4 times a month, mostly without orgasm. The last coitus which happened in side-by-side position was accompanied by orgasm which continued in uterine hypertonicity and massive vaginal bleeding at 29 weeks gestation. Two hours subsequently, on admission to hospital, placental abruption and fetal demise were diagnosed. At the emergency cesarean section, a dead female infant weighing $1,510 \mathrm{~g}$ was born. Fetal pathology was not discovered. Placental histopathology showed retroplacental hematoma, intervillous and decidual hemorrhages, focal distal villous hypoplasia and avascular villuses. Patient's recovery rapidly occurred after intensive care.

Placental abruption complicates $0.4 \%-1.0 \%$ of deliveries. It is known that most cases of abruption cannot be predicted and prevented. Our report suggests that orgasmic coitus may be a trigger for placental abruption in those women who have gestational hypertension and multiple risks for placental abruption. We infer from the above case that sexual intercourse is advised to avoid during pregnancy of such women in order to prevent placental abruption.

\section{More Information}

*Address for Correspondence: Dr. Attila Pajor, Semmelweis University Faculty of Medicine, Department of Obstetrics and Gynecology, H-1082 Budapest, Üllöi ut 78/a, Hungary, Email: pajor.attilak@gmail.com

Submitted: 20 November 2019

Approved: 20 December 2019

Published: 23 December 2019

How to cite this article: Zsoldos M, Vezér M, Pusztafalvi H, Pencz B, Hargitai D, et al. Orgasmic coitus triggered stillbirth via placental abruption: A case report. Arch Case Rep. 2019; 3: 056-058

DOI: dx.doi.org/10.29328/journal.acr.1001026

Copyright: ( 2019 Zsoldos M, et al. This is an open access article distributed under the Creative Commons Attribution License, which permits unrestricted use, distribution, and reproduction in any medium, provided the original work is properly cited.

Keywords: Orgasm; Coitus; Stillbirth; Preterm; Placental abruption

W) Check for updates

OPEN ACCESS

\section{Introduction}

Premature separation of the placenta, i. e. placental abruption is a severe condition complicating $0.4 \%$ to $1.0 \%$ of deliveries [1,2]. It is one of the ischemic placental diseases [3]. There are many chronic clinical conditions and epidemiological factors that increase the risk of placental abruption $[1,2,4]$. Most cases of placental abruption, however, cannot be predicted [1,5]. Sexual activity in pregnancy is regarded safe [6-8]. In contrast to this, we hereby report a case demonstrating that orgasmic coitus triggered placental abruption resulting in stillbirth.

\section{Case History}

A 38-year-old Caucasian woman (8-para, 12-gravida, body mass index 30.1) was brought into hospital by ambulance after developing severe vaginal bleeding at 29 weeks gestation. Her last antenatal appointment was 5 weeks preceding admission when ultrasound examination showed eutrophic fetus. No anemia and diabetes were shown during the antenatal period but she had gestational hypertension successfully treated with nifedipine ( 2 × $20 \mathrm{mg}$, Cordaflex, EGIS). Patient lived unmarriedly with a constant partner in low socioeconomic conditions. Her past medical history revealed no illness. Her previous 7 pregnancies and deliveries including one twin pregnancy were without complications. In addition, she had two pregnancy terminations and her two pregnancies ended in first trimester miscarriage.

On admission, patient had massive uterine bleeding with 
a tachycardia of 110 b.p.m. and blood pressure of 110/70 mmHg. Her temperature was normal. Physical examination revealed uterine hypertonicity and tenderness, regular labor pains with uterine mouth dilated to $5 \mathrm{~cm}$, and with intact fetal membranes. The fetus was in breech presentation. Ultrasonography showed an eutrophic fetus without fetal heart activity, normally implanted placenta and retroplacental hematoma measuring $4 \times 5 \mathrm{~cm}$. Urgent laboratory tests showed that she had hemoglobin of $9.6 \mathrm{~g} / \mathrm{dl}$, hematocrit of $27 \%$, platelet of $140 \times 10^{9} / \mathrm{l}$, total white cell count of $19.6 \times$ $10^{9} / \mathrm{l}$, INR of 2.0, D-dimer $>38.85 \mathrm{mg} / \mathrm{l}$ and C-reactive protein of $5.0 \mathrm{mg} / \mathrm{l}$. Liver and kidney function tests were within normal limits. Placental abruption and fetal demise were diagnosed. At the emergency cesarean section, a dead female infant weighing 1,510 g was born. Patient received crystalloid infusion, 6 units of packed red cells and 3 units of fresh frozen plasma then her recovery occurred rapidly and uneventfully. Fetal pathology was normal. Placental histopathology confirmed retroplacental hematoma. Adjacent to it intervillous and decidual hemorrhages were found, furthermore, focal distal villus hypoplasia and avascular villuses were seen. Villous infarctions, increased syncytotrophoblast knotting or pigmented histiocytes were not shown.

In a personal interview following surgery, patient denied intimate partner violence, recent abdominal trauma, vaginal bleeding in the first half of pregnancy, drug abuse, alcohol use and smoking. She told us that she had sexual intercourse during pregnancy 2 to 4 times a month and achieved orgasm only 3 times out of 10 occasions. The last coitus was carried out in side-by-side position in the morning, two hours prior to admission and her orgasm turned to permanent low abdominal pain then vaginal bleeding appeared. Thereafter she experienced periodic uterine contractions.

\section{Discussion}

In the above report, the time proximity between the coitus and placental abruption suggests, similarly to a previous case report [9], that coitus may be a trigger for placental abruption. Data from a large study including 56,568 pregnancies demonstrated that the frequency of antepartum uterine bleeding including placental abruption was higher in women who reported recent coitus compared with those who had no recent coitus [10]. An other study found that among women who had coitus within the 48 hours preceding delivery, placental abruption more often happened than among those who reported no coitus [11]. These studies are in accordance with the above case report.

In addition, our case report has shown that placental abruption triggered by orgasmic coitus occurred in a woman who had multiple risk factors of placental abruption such as high multiparity, low socioeconomic condition, single marital status, advanced maternal age and gestational hypertension. These factors may individually represent risk for placental abruption $[1,2,12]$.
Etiopathogenesis of placental abruption is not well understood. It is characterized by both chronic pathophysiologic features such as uteroplacental underperfusion, chronic fetal hypoxemia [13] or placental ischemia [3], and acute processes such as physical exertion [14], acute inflammation [5], elevated outdoor temperatures in warm seasons [15] and sexual intercourse [9-11].

It is known that sexual activity in late pregnancy can evoke increased pelvic congestion which slowly relieves and may last about 60 minutes following orgasm [16]. In contrast to that coitus does not increase the incidence of preterm and term deliveries [6-8], it has been demonstrated that orgasm in late pregnancy may be accompanied by uterine contractions during which decelerations of fetal heart rate appear and within 15 minutes after the last orgasm, the rhythmic contractions cease $[17,18]$. Consequently, pelvic congestion and uterine contractions working together can acutely impair the uteroplacental perfusion during and following the orgasmic episodes, and thus orgasm may result in placental abruption in those women whose uteroplacental perfusion has already been damaged by chronic processes [5]. The chronic placental disease was proven in our patient as well. Pathomechanism of placental abruption, above outlined is consistent with the findings that pregnant women of advanced maternal age have a higher risk for uterine bleeding following coitus [10], and advanced maternal age is correlated with the imbalance in angiogenic growth mediators and oxidative stress biomarkers [19]. Since the blood pressure during sexual activity increases [20], it may be a contributory mechanism for the abruption, particularly in pregnant women with hypertension.

In women with placental abruption vaginal delivery is usually preferred if the fetus has died [4]. In our patient, however, the uterine hemorrhage was so brisk and massive that promt delivery became necessary in order to stop bleeding quickly. That is why emergency cesarean delivery was chosen.

Our case report has shown that orgasmic coitus triggered placental abruption which resulted in preterm stillbirth in a pluripara woman with gestational hypertension, and the abruption was linked to placental disease.

\section{Conclusion}

It has been concluded that orgasmic coitus may trigger severe placental abruption in women with high risks for placental disease. This knowledge is counselled to apply during the antenatal care in order to prevent placental abruption and its complications, i.e. sexual intercourse is advised to avoid in such pregnancy.

\section{Acknowledgments}

\section{Ethics approval}

Authors state that the study protocol was approved by the Institutional Review Board before the study. 


\section{Informed consent}

Authors confirm that the patient in case report gave written informed consent before the study began.

\section{Author contributions}

MZ conceptualized the study design, drafted and revised the manuscript. MV prepared data for the work and revised the manuscript. HP revised the manuscript. BP and DH carried out pathologic evaluation. AP conducted the study, drafted, wrote and revised the manuscript. All authors approved the final manuscript and agreed to be accountable for all aspects of the work.

\section{References}

1. Oyelese Y, Ananth, CV. Placental abruption. Obstet Gynecol. 2006; 108 1005-1016.

PubMed: https://www.ncbi.nlm.nih.gov/pubmed/17012465

2. Tikkanen M. Placental abruption: epidemiology, risk factors and consequences. Acta Obstet Gynecol Scand. 2011; 90: 140-149. PubMed: https://www.ncbi.nlm.nih.gov/21241259

3. Ananth CV, Vintzileos AM. Ischemic placental disese: epidemiology and risk factors. Eur J Obstet Gynecol Reprod Biol. 2011; 159: 77-82. PubMed: https://www.ncbi.nlm.nih.gov/pubmed/21839575

4. Boisramé $T$, Sananès $N$, Fritz $G$, Boudier $E$, Aissi $G$, et al. Placental abruption: risk factors, management and matenal-fetal prognosis. Cohort study over 10 years. Eur J Obstet Gynecol Reprod Biol. 2014; 179: 100-104.

PubMed: https://www.ncbi.nlm.nih.gov/pubmed/24965988

5. Ananth CV, Oyelese Y, Prasad V, Getahun D, Smulian JC. Evidence of placental abruption as a chronic process: associations with vaginal bleeding early in pregnancy and placental lesions. Eur J Obstet Gynecol Reprod Biol. 2006; 128: 15-21.

PubMed: https://www.ncbi.nlm.nih.gov/pubmed/16513243

6. Omar NS, Tan PC, Sabir N, Yusop ES, Omar SZ. Coitus to expedite the onset of labour: a randomised trial. Br J Obstet Gynaecol. 2013; 120: 338-345.

PubMed: https://www.ncbi.nlm.nih.gov/pubmed/23145957

7. Carbone L, De Vivo V, Saccone G, D’Antonio F, Mercorio A, et al. Sexua intercourse for induction of spontaneous onset of labor: A systemic review and meta-analysis of randomized controlled trials. J Sex Med. 2019; 16: 1787-1795.

PubMed: https://www.ncbi.nlm.nih.gov/pubmed/31521572

8. Sayle AE, Savitz DA, Thorp JM Jr, Hertz-Picciotto I, Wilcox AJ. Sexual activity during late pregnancy and risk of preterm delivery. Obstet Gynecol. 2001; 97: 283-289.

PubMed: https://www.ncbi.nlm.nih.gov/pubmed/11165596
9. Aziken ME. Abruptio placenta following sexual intercourse: case report. Niger Postgrad Med J. 2003; 10: 113-114.

PubMed: https://www.ncbi.nlm.nih.gov/pubmed/14567049

10. Naeye RL. Coitus and antepartum haemorrhage. $\mathrm{Br} \mathrm{J}$ Obstet Gynaecol. 1981; 88: 765-770.

PubMed: https://www.ncbi.nlm.nih.gov/pubmed/7248236

11. Brink AL, Odendaal HJ. Risk factors for abruptio placentae. S Afr Med J. 1987; 72: 250-252.

PubMed: https://www.ncbi.nlm.nih.gov/pubmed/3616809

12. Räisänen $S$, Gissler $M$, Nielsen HS, Kramer MR, Williams MA, et al. Social disparity affects the incidence of placental abruption among multiparous but not nulliparous women: a register-based analysis of 1,162,126 singleton births. Eur J Obstet Gynecol Reprod Biol. 2013; 171: 246-251.

PubMed: https://www.ncbi.nlm.nih.gov/pubmed/24094822

13. Morales-Roselló J, Khalil A, Akhoundova F, Salvi S, Morlando M, et al Fetal cerebral and umbilical Doppler in pregnancies complicated by late-onset placental abruption. J Matern Fetal Neonatal Med. 2017; 30: 1320-1324.

PubMed: https://www.ncbi.nlm.nih.gov/pubmed/27484964

14. Chahal HS, Gelaye B, Mostofsky E, Sanchez SE, Mittleman MA. et al. Physical exertion immediately prior to placental abruption: A casecrossover study. Am J Epidemiol. 2018; 1287: 2073-2079. PubMed: https://www.ncbi.nlm.nih.gov/pubmed/29992226

15. He S, Kosatsky T, Smargiassi A, Bilodeau-Bertrand M, Auger N, et al. Heat and pregnancy-related emergencies: Risk of placental abruption during hot weather. Environ Int. 2018; 111: 259-300.

PubMed: https://www.ncbi.nlm.nih.gov/pubmed/29146008

16. Polomeno V. Sex and pregnancy: A perinatal educator's guide. J Perinatal Educ. 2000; 9: 15-27.

PubMed: https://www.ncbi.nlm.nih.gov/pmc/articles/PMC1595041/

17. Chayen B, Tejani N, Verma UL. Fetal heart rate changes and uterine activity during coitus. Acta Obstet Gynecol Scand. 1986; 65: 853-855. PubMed: https://www.ncbi.nlm.nih.gov/pubmed/3825526

18. Goodline RC, Schmidt W, Creevy DC. Uterine tension and fetal heart rate during maternal orgasm. Obstet Gynecol. 1972; 39: 125-127. PubMed: https://www.ncbi.nlm.nih.gov/pubmed/5008272

19. Odame Anto E, Owiredu WKBA, Sakyi SA, Turpin CA, Ephraim RKD et al. Adverse pregnancy outcomes and imbalance in angiogenic growth mediators and oxidative stress biomarkers is associated with advanced maternal age births: A prospective cohort study. PLoS One. 2018; 13: e0200581.

PubMed: https://www.ncbi.nlm.nih.gov/pubmed/30016351

20. Palmeri ST, Kostis JB, Casazza L, Sleeper LA, Lu M, et al. Heart rate and blood pressure response in adult men and women during exercise and sexual activity. Am J Cardiol. 2007; 100:1795-1801.

PubMed: https://www.ncbi.nlm.nih.gov/pubmed/18082530 